\title{
The Generic and Registerial Features of Facebook Apology Messages Written by Americans and Jordanians
}

\author{
Basem I. M. Al-Raba'a ${ }^{1,2}$ \\ ${ }^{1}$ Department of Near Eastern Languages and Cultures, Indiana University Bloomington, Indiana, USA \\ ${ }^{2}$ Department of English Language and Literature, Yarmouk University, Irbid, Jordan \\ Correspondence: Basem I. M. Al-Raba'a, Department of Near Eastern Languages and Cultures, Indiana \\ University Bloomington, Indiana, Goodbody Hall 219, 1011 E. 3rd St. Bloomington, IN 47405-7005, USA. Tel: \\ 1-843-814-2470. E-mail: balrabaa@indiana.edu
}

\author{
Received: January 30, 2013 Accepted: February 18, 2013 Online Published: March 25, 2013 \\ doi:10.5539/ijel.v3n2p54 \\ URL: http://dx.doi.org/10.5539/ijel.v3n2p54
}

\begin{abstract}
This paper aims at investigating the generic and registerial features of Arabic and English apology messages written on Facebook by Jordanian and American university students. The data collected by means of distributing a simulated written paragraph to the participants via Facebook consist of one hundred Arabic and English messages (fifty Arabic and fifty English). The results demonstrate that Arabic and English apology messages written on Facebook share the same communicative purposes, but differ with respect to the number of moves and the lexical and stylistic choices employed by both the Jordanian and American students. The findings of this study have been attributed to the universality of expressing apology, diglossia of Arabic, and to a variation in the subjects' linguistic and sociocultural backgrounds and perceptions.
\end{abstract}

Keywords: genre analysis, contrastive analysis, Facebook messages, apology

\section{Introduction}

It is undeniable that the internet is currently a very significant and recent medium of communication used globally among people. The internet is an association which consists of numerous computer networks through which messages can be sent from one computer to another (Crystal, 2001, pp. 2-3). There is a rapid development in computer-mediated communication over the past decade, which has led to a widespread expansion of the internet and to having online communities (Craig et al., 2007, p. 2). Crystal (2001, p. 94) defines the linguistic identity of e-mail as a variety of language and considers it as a communicative genre. Craig et al. $(2007$, p. 2$)$ points out that Facebook is also a new medium of communication considered as an extension of and similar to other online networks, such as e-mail, in that it allows people to communicate with each other. Facebook is more similar to e-mail than to any other networks since it serves a similar function to that of e-mail, and since most people use their e-mail addresses to log onto Facebook. The slight difference between the two websites is that Facebook is less formal than e-mail and accordingly is used only among friends and acquaintances.

Baron (2000, pp. 247-251) states that e-mail is a medium of communication that has characteristics from both speech and writing (part speech, part writing). Baron (1998, pp. 150-155) suggests that although e-mail is more similar to writing than to speech with regard to the distance between e-mail users as they are physically separated, it has something in common with speech in that e-mail provides its users with more rapid feedback than traditional writing does. Therefore, it can be assumed that e-mail and Facebook, since they are similar, have some characteristics found in speech and writing and accordingly form their own genre and function as a new medium of communication. This new genre is associated with registers that are culture specific.

Swales $(1990$, p. 58) defines genre as a concept which refers to a class of communicative events in which participants share a set of formal, functional and contextual conventions. Bhatia (1993, p. 32) suggests that a generic structure has many elements called moves each of which serves a communicative purpose. The linguistic term 'moves', according to Bhatia (1993, pp. 30-32), can be thought of as several separated elements which all together constitute a generic structure; each move serves a communicative goal consistent with and useful for the overall purpose of the genre. That is, the structure of moves varies from one genre to another, depending upon the communicative purpose(s) that it serves in the genre. Interestingly enough, each genre might have highly or 
slightly different registerial features associated with it. Register, as generally described by Finegan and Biber (1994, p. 239), represents the use of the appropriate varieties of language (spoken and written) in the appropriate situations. Georgakopoulou and Goutsos (1997, p. 34) note that "a genre tends to be identified with a specific style register." According to them, the study of genres is helpful in constructing, organizing and interpreting meaning, and controlling its function in the discourse.

To sum up, genre can be thought of as the structure of discourse determined by the purposes of communication of the text and the social context, whereas register is concerned with the lexical and grammatical choices which are made in the light of the social and contextual features of the discourse. Eventually, it can be hypothesized that the choices of register (immediate contextual variables) employed in a certain genre could be different from one culture to another since they are governed by distinctive social aspects (customs, beliefs, ideas, etc.) of each culture. Thus, it is of paramount importance to analyze the generic and registerial features of the participants' Facebook apology messages in the light of the Jordanian and the American cultures.

\section{Methods}

The study aims to investigate the generic and registerial features of Facebook apology messages written in Arabic and English by Jordanian and American university students. It also seeks to compare and contrast the component moves and registerial features employed by both Jordanian and American students in the light of the Jordanian and the American cultures as an attempt to reveal to what extent the registers and strategies used are similar or different.

The subjects of the study are all university students whose ages range from 19 to 25 years old. They were randomly chosen from both genders (males and females). The sample of the study includes two representative groups randomly selected; the first group consists of fifty Jordanian university students, and the second fifty American university students. The researcher was very keen to choose Jordanian and American students specialized in similar majors in an attempt to make the results of the study more accurate. The researcher thinks that students majoring in similar fields of study might have something in common more than those specialized in different fields.

With respect to the Jordanian students, they were chosen from three Jordanian universities (Yarmouk University, Jordan University of Science and Technology, and Mu'tah University). The Jordanian students are majoring in any of the following fields: English, mathematics, and political science. The American students, on the other hand, were chosen from Tufts University, Lincoln University, and University of California Santa Barbara. The American students are specialized in any of following fields: mathematics, English and mass communication, and global studies.

The researcher collected the data through distributing a simulated written paragraph to the subjects of the study via Facebook. All the messages were written in response to a written paragraph describing a situation in which the subjects imagine that they had promised to meet a close friend of theirs at a certain place, but could not go to that place on that day for some reason. The subjects' task was to send a message to his/her friend on Facebook, apologizing for what happened. The American students received the task in English, whereas the Jordanians received it in Arabic. Then each group wrote the messages in its native language.

After getting the students' apology messages, the researcher divided up the apology messages into eight component moves and contrasted the Arabic and English messages according to the types of moves used in the messages and their number in percentage terms. The apology moves by means of which Facebook messages have been structured were classified as follows: opening, expressing apology, expressing responsibility, justifying, offering repair, promising forbearance, wishing for forgiveness, and ,finally, closing. The researcher followed Kasanga and Lwanga-Lumu (2007) in dividing apology strategies (expression of apology, acknowledgement or expression of responsibility, explanation or giving reasons, offer of repair, and, finally, promise of forbearance), but added three strategies: opening, wishing for forgiveness, and closing.

\section{Review of Related Literature}

This section tackles the previous literature related to the current study, focusing upon those studies conducted on the generic and registerial features of e-mail messages and comparing the language of e-mail with that used in traditional writing.

E-mail and Facebook, as mentioned above, are new means of communication the language of which can be considered as an amalgam of spoken and written language. Email, unlike Facebook, has been studied by many linguists as a new medium of communication. The studies conducted on Facebook, up to the researcher's knowledge, have tackled only the uses and gratifications of Facebook, such as Mazer et al.'s (2007), Stern and 
Taylor's (2007), Sheldon's (2008), and Raacke and Bonds-Raacke's (2008). Due to the fact that Facebook is a very recent network and due to the scarcity of studies, specifically in the field of linguistics, on Facebook, the literature review will be about studies conducted on e-mail, those which are somewhat related to the present study.

In his cross-cultural study, Al-Ali (2004) investigates the generic structure of job application letters written by native speakers of Arabic and English. The researcher bases his study on move structure analysis proposed by Bhatia (1993). The results demonstrate that both the Arabic and English cultures have an impact on and govern the stylistic and lexical choices employed by the subjects of the study when writing job application letters even though writing such letters constitutes one genre in both cultures. For example, the subjects' salutations in the openings of the letters are influenced by their cultural backgrounds. The results also reveal that English native speakers, unlike Arabs who are found to invoke employers' compassion and compliment them and their institutions as well, focus on showing their academic and professional qualifications to employers and request interviews.

In a study of e-mail communication among Jordanian university students, Al-Khatib (2008) investigates the extent to which Jordanian students of English communicate via e-mail, and whether or not writing through e-mail signals the appearance of a new genre. The analysis of the data is based on many views and theories, on spoken and written discourse communication, proposed by Hymes (1972), Blom and Gumperz (1972), Swales (1990, 1999), Danet (2002, 2003), Herring (2002, 2003), Crystal (2001) among others. The results reveal that the mode of e-mail messages written by the subjects is different from that employed in personally handwritten letters, and that such messages, used for several communicative purposes, have their own respective characteristics. Furthermore, the study shows that sociological factors such as gender and religion and local communication strategies govern what e-mail messages contain.

Sahawneh (2008) studies formal e-mail request messages written in English by Jordanian and American students in order to investigate the generic and registerial features employed by Jordanians and Americans, and compare the Jordanian students' performance with that of the American native speakers. The researcher bases her study on the move structure analysis done by Bhatia (1993) and developed by Al-Ali (2004). The findings reveal that although the examined e-mails shared the same communicative purpose, it appeared that the generic components and the registerial features used by the Jordanian students did not generally match those used by the American students in terms of the type, number, and frequency of genre moves and the registers employed to structure genre texts. These differences were, according to her, ascribed to the linguistic and sociocultural backgrounds of the Jordanian and American students.

The abovementioned studies indicate that the language of the internet is somewhat different from traditional writing with respect to the linguistic and stylistic features employed, and that culture partly shapes ideas and has a tremendous impact on the lexical and stylistic choices. The relation between language and culture and the similarities and differences between languages as well as ways of communication need further investigation. However, there are no studies, to the best of the researcher's knowledge, conducted on the genre components and the registerial features of Facebook messages. Therefore, the study of the generic and registerial features of Facebook apology messages written in Arabic and English by Jordanian native speakers of Arabic and American native speakers of English will fill the gap in the literature.

\section{Results}

This section sets forth the results and discussion of data analysis, namely a comparison and contrast between the Jordanian and American students' Facebook apology messages with respect to the type and number of component moves occurring in the subjects' data analyzed in percentage terms. Then, the results are discussed and explained in reference to the subjects' linguistic and sociocultural backgrounds.

\subsection{Component Moves of the Jordanian and American Students' Facebook Messages}

The analysis of the Jordanian and American students' data demonstrates that there are eight component moves of which the Arabic and English Facebook messages are composed. The moves employed by both subject groups are shown in Table 1 below; they are organized in a way that best matches the arrangement of those moves presented in around half of the subjects' messages; i.e., the moves are arranged as they mostly appeared in the messages. 
Table 1. Component moves of Jordanian and American Facebook messages

\begin{tabular}{|c|c|c|c|}
\hline Component moves & $\begin{array}{l}\text { Moves in Jordanian } \\
\text { messages \% }\end{array}$ & $\begin{array}{l}\text { Moves in } \\
\text { messages \% }\end{array}$ & American \\
\hline Opening & 100 & 94 & \\
\hline Expressing apology & 72 & 96 & \\
\hline Expressing responsibility & 32 & 46 & \\
\hline Justifying (giving reason(s)) & 100 & 100 & \\
\hline Offering repair & 60 & 90 & \\
\hline Promising forbearance & 6 & 18 & \\
\hline Wishing for forgiveness & 76 & 18 & \\
\hline Closing & 96 & 84 & \\
\hline
\end{tabular}

As shown in the table above, the two subject groups involved in the study employed the same strategies in their apology messages on Facebook, but with variation in the number of moves used. Below are the results individually presented in every single move:

\section{Opening}

The main function of this generic move (opening) is to open a message with an expression for the sake of saluting or naming the addressee. The data reveals that the occurrence of openings in the Jordanians' data is $100 \%$ and that in the Americans' data is $94 \%$. This move comprises a number of various registerial features of opening a message, employed by the two groups. The following Tables ( 2 and 3 ) show the openings chosen by the Jordanians and the Americans respectively:

Table 2. The Jordanians' openings

\begin{tabular}{|c|c|}
\hline Openings & Percentage \\
\hline $\begin{array}{l}\text { 1. Bismi llahi rraћmani raћim } \\
\text { (In the name of Allah, the } \\
\text { Most Merciful, the Most } \\
\text { Gracious) }\end{array}$ & 14 \\
\hline $\begin{array}{l}\text { 2. ?assalamu Salaykum } \\
\text { (Peace be upon you) }\end{array}$ & 20 \\
\hline 3. Marhaba (Hi) + First name & 20 \\
\hline 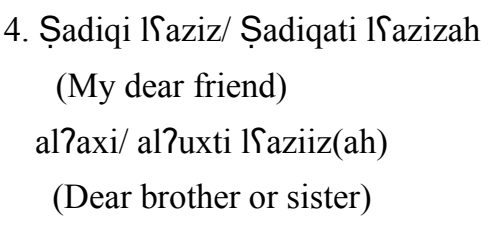 & 24 \\
\hline $\begin{array}{l}\text { 5. Șadiqi/ Șadiqati } \\
\text { (My (male/ female) friend) } \\
\text { + first name }\end{array}$ & 6 \\
\hline 6. Hai $(\mathrm{Hi})+$ first name & 10 \\
\hline 7. Salam $(\mathrm{Hi})+$ first name & 4 \\
\hline 8. Masa?i lxer (Good evening) & 2 \\
\hline
\end{tabular}


Table 3. The Americans' openings

\begin{tabular}{lc}
\hline Openings & Percentage \\
\hline 1. The addressee's first name & 6 \\
2. Dear + first name & 20 \\
3. Hello + first name & 2 \\
4. Hi + first name & 10 \\
5. Hey/ hey + first name & 40 \\
6. Hey man or buddy & 10 \\
7. Yo & 4 \\
8. Boy & 2 \\
\hline
\end{tabular}

It is noticeable from the tables that approximately one third of the Jordanians, on the one hand, opened their messages with religious expressions. On the other hand, no religious expressions were found in the American openings. Regarding the formal openings, $24 \%$ of the Jordanians employed formal expressions, such as 'Șadiqi 1 Saziz' (My dear (male) friend), '?al?uxti 1Sazizah' (Dear sister), whereas 20\% of their American counterparts opened their messages with 'Dear' followed by the first name. Both the Arabic and English messages obviously indicate that the percentage of the Jordanian formal openings all together, including the religious ones, is much higher than that of the American formal openings, (58\% versus 20\%). This finding which will be further explained in the discussion section below has to do with diglossia in Arabic.

On the contrary, the Americans' use of informal expressions which marked most of their openings showed higher frequency than that of their Jordanian counterparts. While informal openings occurred in $80 \%$ of the Americans' corpus, they occurred in only $42 \%$ of the Jordanians'. The informal openings employed by either side more or less differ in terms of the degree of informality (high or low). The Americans used opening expressions of lower degrees of informality than their Jordanian counterparts did.

It should be noted that 'Hai' (Hi) which $10 \%$ of the Jordanians employed as an opening word has been borrowed from English and is sometimes informally used for exchanging greetings among young friends in Jordan nowadays.

\section{Expressing Apology}

Apologizing is a way in which the speakers normally make statements expressing that they really and truly regret their bad behaviors or wrongdoings in order to placate and please the hearers (Olshtain, 1989, p. 156). This component move (apologizing) is realized by making formal or informal statements. The data shows that the subjects employed either formal or informal apologetic expressions in their messages. Table (4) below displays the percentages of both types of expressions used by both subject groups:

Table 4. The Jordanian students' (JS) and American students' (AS) expressions of apology

\begin{tabular}{lclc}
\hline $\begin{array}{l}\text { Arabic apologetic } \\
\text { expressions }\end{array}$ & Percentage & $\begin{array}{l}\text { English apologetic } \\
\text { expressions }\end{array}$ & Percentage \\
\hline $\begin{array}{l}\text { ?aStaðir (I apologize)/ } \\
\text { ?uqaddimu Stiðari } \\
\text { (I express my apology) }\end{array}$ & 46 & I apologize & 12 \\
?ana ?asif/ & & & \\
?asifah (I (male, & 26 & I am sorry/ sorry & 84 \\
Female) am sorry) & & & \\
\hline
\end{tabular}

The formal way of apology is found to be realized by the expression 'I apologize' and its Arabic counterparts. The Jordanians tended to apologize to the addressees more formally than the Americans did; while the former employed formal expressions with a percentage of $46 \%$, the latter did so with a percentage of only $12 \%$. 
Concerning the apologetic 'sorry', the overwhelming majority of the Americans employed the word 'sorry' (84\%), whereas only $26 \%$ of the Jordanians did so. The former appear to be much more informal than the latter in terms of the use of informal expressions of apology.

\section{Expressing Responsibility}

Admitting fault is a strategy apologizers employ to openly and truly acknowledge that they have done something wrong or caused offence to other people. In spite of the fact that all the subjects of the study apologized for their wrongdoings, not all of them made direct remarks, other than the expressions of apology, informing the addressees that they still feel remorseful for what they had already done. However, the American students made more remarks of taking responsibility (46\%) than their Jordanian counterparts did (32\%). The following are illustrative examples (JS stands for the Jordanian students and AS for the American students):

(1) "Zana baSrif ?innak zaSlan Salay wamutadayeq". (JS)

(I know that you are angry and upset with me)

(2) “...Wakan lazim ?arsellik resalah min qabl”. (JS)

(I should have sent you (female) a message before)

(3) "I definitely should have let you know earlier." (AS)

(4) "I felt really bad for not calling you to let you know I couldn't make it". (AS)

\section{Justifying (Giving Reason(s))}

The function of this component move is to give reasons, justifying why the writers missed the appointments with the addressees. All the Jordanian and American students employed this strategy in their messages $(100 \%$ for each group). The reasons given can be classified into two categories: urgent reasons and non-urgent reasons. Table (5) below displays which percentages of both sides gave which reasons:

Table 5. The percentages of urgent and non-urgent reasons given by Jordanian and American students

\begin{tabular}{lcc}
\hline Subject groups & Urgent reasons \% & Non-urgent reasons \% \\
\hline The Jordanians & 52 & 48 \\
The Americans & 22 & 78 \\
\hline
\end{tabular}

Urgent reasons, on the one hand, are usually given in apologies to provide apologizees with justification clarifying that the occurrence of an event has been impeded by the happening of uncontrollable circumstances which require those people who, in one way or another, have something to do with what has already happened to take actions immediately. Under such difficult circumstances, unpleasant events such as death, illness, car accidents, and so forth happen unexpectedly because they are out of control or beyond human power. The data reveals, as shown in Table 4, that such reasons occurred in 26 instances in the Jordanians' data (52\%) and in 11 instances in the Americans' (22\%). The following examples illustrate:

(5) “... Bassilli Șar ใinuh wa?ana țaliS laSindak haṢala hadith qiddami maS ?ibin jiranna wama qdert ?atrukuh bidun musaYadeh". (JS)

(But what happened is that while I was coming to you, my neighbor had an accident in front of me, and I could not leave him without help)

(6) "kanat walidati mariḍah wakana yajib Salayna ?an na?xuðaha ?ila lmustashfa bisur $a$ ah.” (JS)

(My mother was ill and we had to take her to the hospital quickly)

(7) "One of the girls came back with a sprained ankle and I had to help her get situated". (AS)

(8) "My cousin went into a diabetic coma and I had to be the one in charge of the kids while she went to the hospital." (AS)

Non-urgent reasons, on the other hand, are also given to justify what prevented apologizers from meeting appointments, but the occurrence of an event in this case is hindered by the happening of non-difficult situations, such as forgetting, being busy, going to another place, etc. The American students justified their attitudes, giving non-urgent reasons with a percentage of $78 \%$ as opposed to the Jordanians who did so with a percentage of $22 \%$. 
Below are some examples:

(9) “Fabaynama kuntu ?urattibu nafsi lilqudum ja?a liziyaratina dar xali”. (JS)

(As I was getting ready, my uncle and his family visited us)

(10) "Lam Zastați i lqudum li?anahu kana Sindi mawSid Sind duktor". (JS)

(I could not come because I had an appointment with a doctor)

(11) "My alarm clock malfunctioned". (AS)

(12) "I got tied up during classes and then I lost my phone." (AS)

Furthermore, the Jordanians most often gave their reasons in details and elaborated on them more than the Americans did. Besides, a few of the subjects of both groups did not mention any reasons, but rather justified their attitudes by only informing the addressees that they could not come for personal or private reasons. The Jordanians who justified their attitudes in such a way are merely $6 \%$ compared to their American counterparts who did so with a percentage of $16 \%$.

\section{Offering Repair}

This component move is used by speakers or writers to offer the addressees what might better an unpleasant situation, or rather what could render a bad situation better. Thus, apologizers usually utilize this as a compensation strategy. It was found that $60 \%$ of the Jordanians employed this move, whereas $90 \%$ of their American counterparts did so. The following are illustrative examples:

(13) "Kun wathiq ?anni sawfa ?azuruka fi lbayti qariban." (JS)

(Be sure that I am going to visit you at home soon)

(14) "Sala ?amali lliqa?i bika fi ?aqrabi waqt." (JS)

(Hopefully, we will meet at the earliest possible time)

(15) "I promise I will make this up to you." (AS)

(16) "I really hope we can work out another time to get together." (AS)

\section{Promising Forbearance}

This move stands for a categorical statement (promise) to which apologizers usually resort in order to truly show that what they have done (their wrongdoings) will never happen again. Forbearance was found to be the least used move by the subjects in their apology messages, where it occurred in merely three cases of the Jordanians' corpus (6\%), and in nine cases in the Americans' (18\%). The examples below illustrate:

(17) “... Welmarra ljay ?insha?a allah sawfa ?ahọur fi lwaqti lmuћaddad”. (JS)

(Next time, God willing, I will come at the determined time)

(18) "?in sha?a allah lmarra lthaniah nitlaqa waji Sala nafsi lmawSid". (JS)

(God willing, we will meet each other next time, and I will come on time)

(19) "Let me know when you are free, and I promise I will be there!" (AS)

(20) "I promise I'll show up this time." (AS)

\section{Wishing for Forgiveness}

This move is occasionally used to beg the apologizees' forgiveness. The data analysis demonstrates that $76 \%$ of the Jordanian students asked the addressees for forgiveness as opposed to their American counterparts who did so with a percentage of only $18 \%$. It was also found that the 'Wishing for Forgiveness' move is realized, in both Arabic and English, either by begging the addressee's forgiveness directly, such as 'please forgive me', 'I beg your forgiveness', etc., or indirectly, namely hinting at forgiveness with the use of indirect expressions or statements, such as 'I hope you do not hate me now', 'I hope you accept my apology', 'I hope you are not angry at me', and so forth. Both subject groups employed the above two ways of begging forgiveness in their apology messages, the examples of which are:

(21) "?arju ?an taqbali lil?iৎtiðar". (JS)

(Please, accept my apology)

(22) “Batmanna ma tkuni zaSlaneh'. (JS)

(I hope you are not angry) 
(23) "I hope you will understand and accept my apology." (AS)

(24) "I hope you aren't too pissed about me flaking". (AS)

\section{Closing}

It is the final part of the apology messages the subjects wrote on Facebook. Most of the messages examined contain closings, where $96 \%$ of the Jordanians concluded their messages with closing expressions, and $84 \%$ of the Americans did so. Such closings normally imply expressions showing respect, love, loyalty, and so forth. The Arabic closings appeared to be much more formal than the English ones. Below are illustrative examples where ' $\mathrm{X}$ ' stands for the first name and ' $\mathrm{Y}$ ' for the last name:

(25) "?axuk X

Wassalamu Salaykum”. (JS)

(Your brother X, and peace be upon you)

(26) "MaS xaliṢ hubbi wataqdiri liṢadiqati wa?uxti 1Sazizah

Wassalamu Salaykum". (JS)

(With all my love and appreciation to my dear friend and sister and peace be upon you)

(27) "Love

X”. (AS)

(28) "See you soon, man.

X”. (AS)

\section{Discussion}

The results of the analyzed component moves in question demonstrate that the component moves of which Facebook apology messages are composed share the same communicative purposes, but the variation lies in the percentages of the moves employed by both the Jordanian and American students. The notion that apology is universal could be the main reason behind there being a striking similarity between the Jordanian and American students in employing the same strategies of apology. However, this section includes a contrast between the linguistic and registerial features employed by the two groups, and how their choices are governed by the social and cultural factors.

The opening section displays some variation in styles of opening a message and addressing a friend. The fact that there are cultural differences in opening an apology message is actually evident in both groups' data. The Jordanians' registers in this generic move are much more formal than those of their American counterparts. This can be ascribed to diglossia for which Arabic is renowned and which Arabic, unlike English, speakers face. Speakers of Arabic "have been described as diglossic speech communities, i.e., communities in which two varieties of a single language exist side by side" (Bassiouney, 2009, p. 10). Simply put, Standard Arabic is used in writing and formal speeches, whereas colloquial vernaculars in informal situations. The fact that writing is normally associated with Standard Arabic clarifies why most Jordanian students tend to be formal. On the other hand, the informality of the situation (apologizing to a friend on Facebook) justifies the use of Jordanian colloquial Arabic in writing. In fact, the phenomenon of writing in colloquial Arabic is still in its infancy; this phenomenon has recently started to prevail among the Arab youth in computer-mediated communication, such as Facebook, Twitter, and Skype.

In addition, the Jordanian students' formal opening expressions include religious terms. Thirty-four percent of the Jordanian openings were religious as they contain lexical items which came from Islam (see Table 2), whereas none of the American students used religious openings. Opening the messages with religious expressions by some Jordanian students can be attributed to the idea that the Jordanians are highly influenced by Islam which is an inseparable part of the Arabic culture in general and the Jordanian culture in particular. Al-Ali (2004, p. 17) found out, in his cross-cultural study on job application letters written by native speakers of Arabic and English, that the Arabic culture of which Islam is a part governs the lexical choices used by Arabs in the opening sections when writing job application letters. The fact that none of the Americans used religious lexical terms refers to the idea that most Americans, especially the youth, are not concerned with religious openings as Muslims.

The data also reveals that the Jordanian students (males and females) addressed only hypothetical friends of the same gender, and this was absolutely their default option. The Americans, instead, addressed hypothetical friends of both genders, regardless of their being males or females. Therefore, the former directly hypothesized that they 
were to address friends of the same gender, which indicates that there are cultural, religious, conventional restrictions on this matter. Gender segregation is still a part of the Jordanians' lives or traditions in some aspects of life. Al-Khatib (2008, p. 9) notes that the segregation of genders is one of the major features by which the Arab society is characterized. Additionally, it is the Arabic cultural norms and religion which impose restrictions on a male-female relationship.

In the 'expression of apology' move, the Jordanian and American students' apologetic expressions were found to be somewhat different in formality and politeness, which might very likely be related to variation in the cultural norms of the Jordanian and American societies. Both Jordanians and Americans appear to be very polite and psychologically affected by what had happened (breaking promises) in that they, in addition to employing apologetic expressions, occasionally reiterated the use of '?ana ?aStaðir'/'I apologize' or/and '?ana ?asif'/'I am sorry', and used intensifiers (adverbs) such as 'haqqan'/'really', 'jiddan'/'very', 'jiddan'/'so', etc. in order to strengthen the degree of politeness. Although the Jordanians were more formal than the Americans, the latter showed higher degrees of politeness.

The Americans used more intensifying adverbs for emphasis than the Jordanians did. Given that, one might assume that the difference in the way of expressing apologies between both subject groups could be ascribed to variation in etiquettes of apologizing in both cultures. In other words, it is the cultural rules, customs, and beliefs which completely govern the way apology is expressed in a society. It seems that it is more important in the American culture to earnestly regret breaking promises by reiterating expressions of apology and/or using intensifiers than it is in the Jordanian culture.

The above finding is somewhat similar to Sahawneh's (2008, pp. 68-69) that American students employ more polite expressions, such as 'thanks', 'I appreciate', etc., at the end of their e-mail messages than Jordanian students do, $(58 \%$ versus $33 \%)$. She attributes this finding to the wide use of polite expressions in every day interactions in the American society.

With regards to the 'expressing responsibility' move, a considerable number of the subjects of both groups completely admitted fault by taking full responsibility, but with some variation. The fact that the Americans made more direct remarks (other than the expressions of apology), acknowledging that they made a mistake compared to their Jordanian counterparts might refer to the notion that Americans might be more likely to take responsibility than Jordanians partly because Americans, unlike most Jordanian university students, leave their families and live on their own around the age of eighteen, which very likely makes them more responsible. The Jordanian society is normally formed by communities in which individuals have more collective than individual responsibilities; i.e., Individuals usually consult one another in decision-making and assuming responsibility. By and large, Jordanian university students mostly tend to depend on the elderly. However, further research exploring the way Arab and American adolescents and adults grow to assume responsibility is needed to support this claim.

As for the 'justifying' move (giving reason(s)), the Jordanians happened to give urgent reasons more than non-urgent reasons as opposed to their American counterparts. The former also gave more detailed and elaborate explanations than the latter did. Such variations could be related to the subjects' different cultural perceptions which are evidently reflected in the given reasons in question. There might be a cultural variation in the degrees of credibility standards or formality, and directness. It seems that the standards of credibility are higher in the American culture than those in the Jordanian culture. The American society seems to be more frank than its Jordanian counterpart. Thus, the justifications given by the Americans might be naïve and unconvincing enough in the Jordanian standards. The formality of the situation for the Jordanians could be another explanation for giving many urgent reasons. That is to say, this has to do with the diglossia of Arabic and the differences between written and spoken language.

With respect to the length and the number of reasons examined in this move, the data shows that the Jordanians made more profuse justifications than the Americans did (the latter were found to be more direct than the former). In general, such a difference in directness could be related to the concept of time which is of more value for the Americans than it is for their counterparts. Therefore, it is the nature of the American life, which makes Americans come straight to the point, i.e., employing the least possible words to convey a certain piece of information in a short period of time. For example, many American students concluded the 'justifying' move with expressions such as 'I will explain to you later'. This also indicates how significant time is in the American culture.

It is not uncommon that time is valued in the Jordanian culture, but most Jordanians, especially university students, are less careful with time than their Americans are. The latter, unlike the former for whom parents and sometimes older brothers are responsible particularly during their university life, have a lot of duties and are responsible for their lives, which as a result renders them studiously value the gravity of time. 
Concerning the 'offering repair' move, the Americans appear to be a little more polite and considerate towards their friends' feelings than the Jordanians in that they used statements, such as 'can't wait to catch up with you', 'I promise', 'I definitely will...', etc., which might have a stronger effect on the addressee than those employed by the latter. Such variation in politeness could be attributed to the subjects' different cultural backgrounds. It seems logical to assume that the Americans are more concerned with time and punctuality, for they expressed stronger expressions of apology and offering repairs.

The above finding is advocated by Sahawneh's (2008, p. 69) that American students employ, in their formal email messages, the apologetic expression 'I apologize/ express my apology' more than Jordanian students do. She suggests that the Americans seem to be more punctual and highly value doing time. Breaking deadlines, she adds, seems unusual for the Americans. Patai (1973, pp. 65-66) notes that Westerners concern themselves over time much more than Arabs do. Westerners are always aware of the importance of time and have busy timetables. He adds that even though Arabs, under the influence of Westernization, have recently considered timetables, schedules and the like as important factors of their lives, there still exists a traditional lack of concern with time in some parts of the Arab world, especially in small towns. Where a Westerner would determine the exact time, say at five in the afternoon, when promising to meet somebody, the Arab would say 'see you in the afternoon', referring to any time from early afternoon to late in the evening.

With regards to the 'promising forbearance' component move, the Americans showed more propensity for forbearance (promising not to miss future appointments) than the Jordanians did. The reason could be related, as I mentioned in the previous move, to the concept of punctuality. Put simply, punctuality is directly proportional to forbearance, i.e., the more punctual one is the more likely one shows forbearance should one miss an appointment. Besides, there is a stylistic variation in showing forbearance; the Americans frequently employed the expressions 'I promise' occasionally accompanied by 'this will not/ never happen again' and sometimes by 'I will be on time', whereas, their counterparts used the expression '?insha?a allah' (God willing). The participants' cultural values indeed affect their linguistic choices; the expression '?insha?a allah' (God willing) is normally used by Jordanians when making promises. In other words, such an expression can pragmatically stand for a promise.

In the 'wishing for forgiveness' move, it appears that the majority of the Jordanians, unlike their American counterparts, asked for forgiveness. The fact that there is a big difference in the percentages of both subject groups in terms of begging forgiveness could also be described in relation to cultural variation. It seems that asking for forgiveness is a very common feature characterizing the Jordanian society, and is a part of its cultural norms. Thus, invoking compassion might be a strong weapon, as it were, to which Jordanians resort in order to have their addressees forgive them.

Al-Ali (2004, p. 11) came up with similar findings; he found out that the 'invoking compassion' move occurred in the Jordanians' job application letters, but never occurred in the English native speakers'. Al-Ali suggests that invoking compassion in the Jordanians' letters could be accounted for by the idea that the writers think that the more they seek compassion and ask for help, the more their job application letters will be taken into consideration (ibid., p. 16). Sahawneh (2008, pp. 76-77) also notes that Jordanians rely on their emotions in order to have their requests accepted in the 'promoting self' move as opposed to Americans who most often rely on their documents and proofs.

Besides, a few of the Jordanian students, unlike their counterparts, asked the addressees for forgiveness by means of making complimentary remarks about the addressees. The following are illustrative examples:

(29) "BaSrif Zalbik țayyeb wakbir."

(I know your (female) heart is kind and big)

(30) “... Fa?ana ZațaS bisamaћati qalbiki wazinata Saqliki wahusni taṢarrufuki”.

(I am after the kindness of your (female) heart, the wisdom of your mind, and your excellent conduct)

The Jordanians tend to be very emotional as opposed to their American counterparts whose ideas seem to be based on reasoning rather than emotions (rational). The latter entirely rely upon taking full responsibility, making offers of repair, and making promises of forbearance, which embodies taking real actions to edify themselves. The former, by contrast, rely on making emotional appeals.

Finally, the Jordanian and American students concluded their Facebook messages with closing expressions reflecting their lexical and stylistic choices. However, the Americans appear to be more informal than the Jordanians in that the former employed expressions used in everyday language as opposed to the latter who were somewhat formal. In other words, the Americans' apology messages including the closings contain a lot of linguistic features of spoken discourse, such as 'see you soon', 'talk to you soon', 'I'll call you later', etc., whereas 
their counterparts' messages have more linguistic features taken from written discourse than those taken from speech, such as 'Ṣadiquka lmuxliȘ' (your loyal friend), 'Șadiqatuki' (your (female) friend) followed by the first name, '?axuka 1Saziz' (your dear brother), and so forth. Such a finding also has to do with diglossia discussed above.

\section{Conclusion}

The fact that expressing apology is universal, on the one hand, could be the main reason for which both subject groups employed similar strategies and share the same communicative purposes in their writing. The variation in the subjects' social and cultural norms and backgrounds (perceptions) and the linguistic norms associated with diglossia in Arabic, on the other hand, evidently appear to be the chief factors beyond having different lexical and stylistic choices used in the Jordanian and American students' apology messages. Eventually, in order for the findings of this study to gain support there is a need for further research with bigger samples and naturalistic data, if possible. Future studies are also needed to consider genre analysis concerning the impact of gender, social class, and age on composing Facebook messages, on the one hand, and the language of these messages in terms of its grammatical structure and/ or meaning, on the other.

\section{References}

Al-Ali, M. N. (2004). How to Get Yourself on the Door of a Job: A Cross-Cultural Contrastive Study of Arabic and English Job Application Letters. Journal of Multilingual and Multicultural Development, 25(1), 1-23. http://dx.doi.org/10.1080/01434630408666517

Al-Khatib, M. (2008). E-mails as a Mode of Communication among Jordanian University Students: A Sociolinguistic Perspective. The International Journal of Language Society and Culture, 25, 1-17.

Baron, N. S. (1998). Letters by Phone or Speech by Other Means: The Linguistics of Email. Language and Communication, 18, 133-170. http://dx.doi.org/10.1016/S0271-5309(98)00005-6

Baron, N. S. (2000). Alphabet to Email. London: Routledge. http://dx.doi.org/10.4324/9780203194317

Bassiouney, R. (2009). Arabic Sociolinguistics: Topics in Diglossia, Gender, Identity, and Politics. Washington, DC: Georgetown University Press. http://dx.doi.org/10.3366/edinburgh/9780748623730.001.0001

Bhatia, V. K. (1993). Analyzing Genre: Language Use in Professional Settings. London \& New York: Longman.

Blom, J., \& Gumperz, J. J. (1972). Social Meaning in Linguistic Structure: Code-switching in Norway. In J. Gumperz, \& D. Hymes (Eds.), Directions in Sociolinguistics (pp. 407-434). New York: Holt, Rinehart and Winston.

Craig, E. et al. (2007). Will You Be My Friend?: Computer-Mediated Relational Development on Facebook.com. Conference Papers - International Communication Association, Annual Meeting, p1-1, 1p.

Crystal, D. (2001). Language and the Internet. Cambridge: Cambridge University Press. http://dx.doi.org/10.1017/CBO9781139164771

Danet, B. (2002). The Language of Email. Invited Lecture, European Union Summer School on Social Representation, Communication and the Internet: University of Rome. Retrieved from http://pluto.mscc.huji.ac.il/ msdanet/papers/email.pdf

Danet, B., \& Susan H. (Eds.). (2003). The Multilingual Internet: Language, Culture and Communication in Instant Messaging, Email and Chat. Retrieved form http://jcmc.indiana.edu/vol9/issue1/

Finegan, E., \& Biber, D. (1994). Register Variation and Social Dialect Variation: The Register Axiom. In P. Eckert, \& J. R. Rickford (Eds.). (2001), Style and Sociolinguistic Variation (pp. 235-267). Cambridge: Cambridge University Press.

Georgakopoulou, A., \& Goutsos, D. (1997). Discourse Analysis: An Introduction (2nd ed.). Edinburgh: Edinburgh University Press.

Herring, S. C. (2002). Computer-Mediated Communication on the Internet. In B. C. Medford (Ed.), Annual Review of Information Science and Technology. NJ: Information Today Inc./American Society for Information Science and Technology.

Herring, S. C. (2003). Gender and Power in Online Communication. In J. Holmes, \& M. Meyerhoff (Eds.), The handbook of language and gender. Oxford: Blackwell. http://dx.doi.org/10.1002/9780470756942.ch9

Hymes, D. (1972). On Communicative Competence. In J. Pride, \& J. Holmes (Eds.), Sociolinguistics: Selected Readings. Harmondsworth: Penguin. 
Kasanga, L. A., \& Lwanga-Lumu, J. (2007). Cross-Cultural Linguistic Realization of Politeness: A Study of Apologies in English and Setswana. Journal of Politeness Research, 3, 65-92.

Mazer, J. P. et al. (2007). I'll See You on "Facebook": The Effects of Computer-Mediated Teacher Self-Disclosure on Student Motivation, Affective Learning, and Classroom Climate. Communication Education, 56(1), 1-17. http://dx.doi.org/10.1080/03634520601009710

Olshtain, E. (1989). Apologies Across Languages. In S. Blum-Kulka, J. House, \& G. Kasper (Eds.), Cross-Cultural Pragmatics: Requests and Apologies, 155-173. Norwood: Ablex Publishing Corporation.

Patai, R. (1973). The Arab Mind. New York: Charles Scribner's Sons.

Raacke, J., \& Bonds-Raacke, J. (2008). MySpace and Facebook: Applying the Uses and Gratifications Theory to Exploring Friend-Networking Sites. CyberPsychology and Behavior, 11(2), 169-174. Mary Ann Liebert, Inc. http://dx.doi.org/10.1089/cpb.2007.0056

Sahawneh, M. (2008). The Generic and Registerial Features of Email Messages Written by American Native Speakers and Jordanian Non-Native Speakers of English (Unpublished master's thesis). Jordan: Jordan University of Science and Technology, Irbid, Jordan.

Sheldon, P. (2008). The Relationship Between Unwillingness-to-Communicate and Students Facebook Use. Journal of Media Psychology: Theories, Methods, and Applications, 20(2), 67-75. The American Psychological Association. http://dx.doi.org/10.1027/1864-1105.20.2.67

Stern, L. A., \& Taylor, K. (2007). Social Networking on Facebook. Journal of the Communication, Speech and Theatre Association of North Dakota, 20, 9-20.

Swales, J. M. (1990). Genre Analysis. Cambridge: Cambridge University Press.

Swales, J. M. (1999). Genre Analysis: English in Academic and Research Settings. Cambridge: Cambridge University Press.

\section{Appendices}

\section{Appendix I}

American Students' Task Description: Writing an English Apology Message on Facebook.

Dear Participant,

Please, reply in a written paragraph to the situation below on Facebook. Your response is of high importance and will be analyzed in a research paper.

Below is the situation:

Imagine that you had promised to meet a friend of yours at a certain place, but you could not go to that place on that day for some reason. Your task is to send a written message to a hypothetical friend on Facebook, apologizing for what happened.

The Jordanian Students received the same task, but in Arabic, and they replied in Arabic as well.

\section{Appendix II}

List of Some Arabic Phonemic Symbols

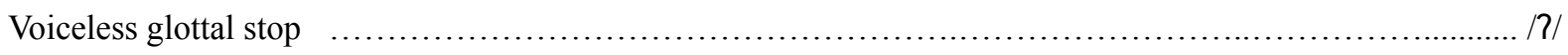

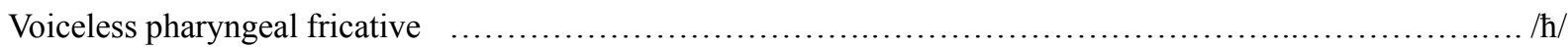

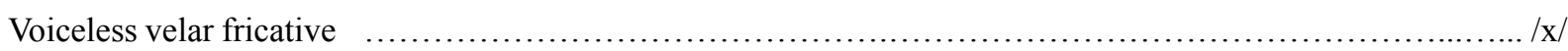

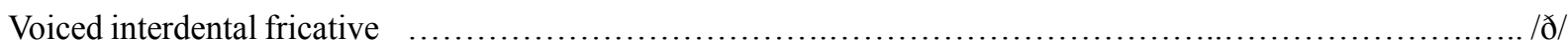

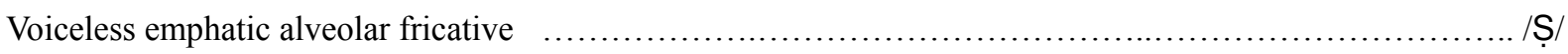

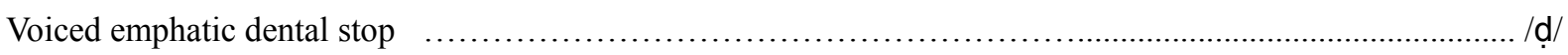

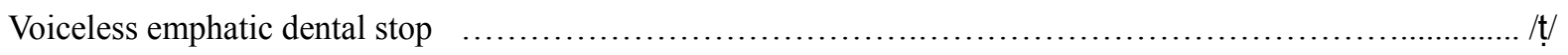

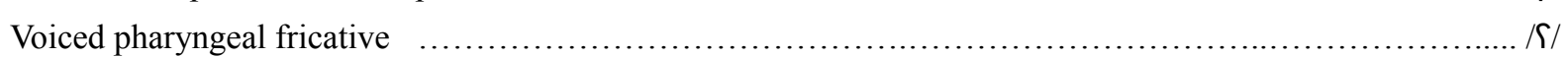

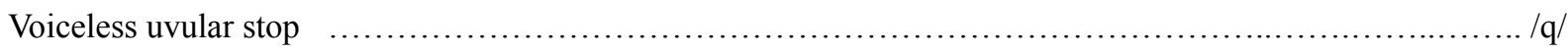

All other symbols are standard 